\title{
Evaluation of bleeding in patients receiving direct oral anticoagulants
}

This article was published in the following Dove Press journal:

Vascular Health and Risk Management

23 August 2017

Number of times this article has been viewed

\section{Erika L Hellenbart ${ }^{\prime}$ \\ Kathleen D Faulkenberg ${ }^{2}$ \\ Shannon W Finks ${ }^{3}$ \\ 'University of Illinois at Chicago College of Pharmacy, Chicago, IL, ${ }^{2}$ Cleveland Clinic, Cleveland, $\mathrm{OH}$, ${ }^{3}$ University of Tennessee College of Pharmacy, Memphis, TN, USA}

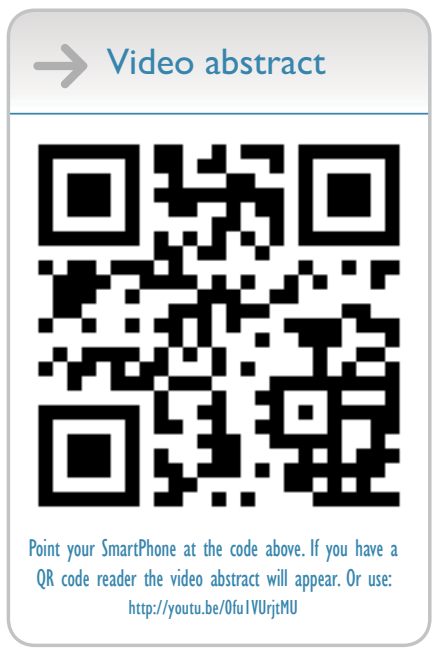

Correspondence: Shannon W Finks University of Tennessee College of Pharmacy, Pharmacy Building Room 459, 88I Madison Avenue, Memphis, TN 38163 , USA

Tel I+90I 448370 I

Fax I+90I 448 I74I

Email sfinks@uthsc.edu

\begin{abstract}
Direct oral anticoagulants (DOACs) are recognized by evidence-based treatment guidelines as the first-line option for the treatment of venous thromboembolism and prevention of stroke and systemic embolism in nonvalvular atrial fibrillation. As use of these anticoagulants has become favored over the past several years, reported bleeding-related adverse drug events with these agents has increased. In randomized clinical trials, all DOACs have a reduced risk for intracranial hemorrhage, while major and other bleeding results have varied among the agents compared to vitamin $\mathrm{K}$ antagonists. We have reviewed the bleeding incidence and severity from randomized and real-world data in patients receiving DOACs in an effort to provide the clinician with a critical review of bleeding and offer practical considerations for avoiding adverse events with these anticoagulants.
\end{abstract}

Keywords: bleeding, direct oral anticoagulants, dabigatran, rivaroxaban, apixaban, edoxaban, post-market bleeding

\section{Introduction}

Direct oral anticoagulants (DOACs) are recognized as guideline-directed medical therapies for the treatment of venous thromboembolism (VTE) and prevention of stroke and systemic embolism (SSE) in nonvalvular atrial fibrillation (NVAF). ${ }^{1-3}$ Previously referred to as new or novel, the DOACs directly inhibit thrombin (dabigatran) or factor $\mathrm{Xa}$ (rivaroxaban, apixaban, edoxaban), thereby exerting their anticoagulant effects. This represents a major advancement over traditional vitamin $\mathrm{K}$ antagonists (VKA), which indirectly affects clotting factors and requires several days to reach peak therapeutic effect. Advantages of using DOACs over VKA include reaching a more rapid anticoagulant effect within hours after first dose, achieving similar (and in some cases superior) effectiveness compared to VKA, eliminating the need for routine international normalized ratio (INR) testing, and improving patient satisfaction. ${ }^{1-3}$ Bleeding remains a risk with any anticoagulant; however, noted differences in bleeding outcomes exist between patients receiving DOACs and VKA. In randomized clinical trials, all DOACs, when used for the prevention of SSE in NVAF, have reduced the risk for intracranial hemorrhage while major and other bleeding results have varied among the agents. ${ }^{47}$ Likewise, when used for the treatment and secondary prevention of VTE, major and nonmajor clinically relevant bleeding seems to be at least similar and sometimes reduced to that of VKA. ${ }^{8-13}$ Global registry data indicate that prescriptions for DOACs have surpassed that of VKA. ${ }^{14}$ As use with these agents has increased since their approval, adverse drug event reporting, in particular bleeding, has also increased. ${ }^{15,16}$ Therefore, a critical evaluation submit your manuscript | www.dovepress.com 
of bleeding in patients receiving DOACs is needed. We have reviewed bleeding incidence and severity from randomized trials and real-world registries in patients receiving DOACs to provide the clinician with a critical review of risk and offer practical considerations for the avoidance and management of adverse events with these anticoagulants.

\section{Evaluation of bleeding events from randomized clinical trials}

Over the past 7 years since the approval of the first DOAC, data from Phase III clinical trials has been scrutinized to better understand and apply both safety and efficacy results to clinical practice. Table 1 summarizes the bleeding end points from each of the Phase III clinical trials utilizing anticoagulation with DOACs in NVAF and VTE treatment. Bleeding was defined as major if it was clinically overt and associated with a decrease in hemoglobin level of $\geq 2.0 \mathrm{~g} / \mathrm{dL}$, if bleeding led to the transfusion of $\geq 2$ units of red cells, or if bleeding was intracranial or retroperitoneal, occurred in another critical site, or contributed to death. Clinically relevant nonmajor (CRNM) bleeding was defined as overt bleeding that did not meet the criteria for major bleeding but was associated with medical intervention, unscheduled contact with a physician, interruption or discontinuation of study drug, or discomfort or impairment of activities of daily life. Studies evaluating the incidence and outcomes of bleeding events from these initial trials have been published and are described in the following sections.

\section{Dabigatran}

Majeed et al ${ }^{17}$ pooled bleeding reports from five major Phase III trials comparing dabigatran and warfarin and reported 7- and 30-day outcomes including mortality in those patients who experienced major bleeding during anticoagulant therapy. In total, 1,121 major bleeds occurred in 1,034 patients with no significant difference in annualized bleeding rates between dabigatran $150 \mathrm{mg}$ twice daily and warfarin (3.32\% vs 3.57\%). Due to its size, most data in the pooled analysis came from the Randomized Evaluation of Long-Term Anticoagulation Therapy (RE-LY) trial, where the majority of bleeding occurred during the longer, 2-year treatment phase of the trial. Length of intensive care unit (ICU) stay was significantly shorter for those patients who experienced major bleeding while on dabigatran than in those with major bleeding from warfarin (1.6 vs 2.7 nights; $P=0.01)$, despite a higher number of patients requiring blood transfusions $(59.2 \%$ vs $49.9 \% ; P<0.001)$ in the dabigatran group. There was a significant decrease in mortality when comparing those patients who experienced a major bleed at 7 days on dabigatran compared to warfarin $(5.3 \%$ vs $8.4 \%$; $P=0.045$ ) and a trend toward reduced mortality at 30 days in those who experienced bleeding on dabigatran vs warfarin (9.1\% vs $13.0 \% ; P=0.057$ ). The 30 -day odds ratio (OR) for the combined dabigatran groups in RE-LY was $0.56(95 \%$ CI 0.36-0.86; $P=0.009)$ and was 0.52 (95\% CI 0.31-0.88) for the dabigatran $150 \mathrm{mg}$ group in the pooled analysis of all five studies. Mortality rates were not reduced in the patients taking dabigatran for the treatment of VTE, but the overall numbers of events were small. Patients who bled while taking dabigatran were found to be older, have worse renal function, and were more likely receiving aspirin or a nonsteroidal antiinflammatory drug (NSAID). Most major bleeding events were managed with supportive care only; for $33 \%$ of major bleeds, no blood products or hemostatic agents were given. Blood transfusion occurred in $59.2 \%$ of patients who bled on dabigatran vs $49.9 \%$ of warfarin $(P=0.002) .{ }^{17}$

\section{Rivaroxaban}

A safety analysis of major bleeding or CRNM bleeding events in the Rivaroxaban Once Daily Oral Direct Factor Xa Inhibition Compared with Vitamin K Antagonism for Prevention of Stroke and Embolism Trial in Atrial Fibrillation (ROCKET AF) trial showed no difference in the risk for bleeding between rivaroxaban and warfarin $(14.91 \%$ vs $14.52 \% ; P=0.442) .{ }^{18}$ Major bleeding was also similar between rivaroxaban and warfarin, but death from major bleeding was significantly less in the rivaroxaban group $(0.24 \%$ vs $0.48 \% ; P=0.003)$, as was intracranial bleeding $(0.77 \%$ vs $1.18 \% ; P<0.05)$. The authors identified age, prior gastrointestinal (GI) bleeding, anemia at baseline, and aspirin use at randomization to be independent predictors of major bleeding. ${ }^{18}$ The EINSTEINDVT and EINSTEIN-PE clinical trials evaluated the use of rivaroxaban vs low molecular weight heparin (LMWH)/VKA therapy for the treatment of VTE. A pooled analysis of these trials showed a similar rate in the principal safety outcome of first major or CRNM bleeding event between rivaroxaban and LMWH/VKA therapy (9.4\% vs 10.0\%; hazard ratio [HR] 0.93 ; 95\% CI 0.81-1.06). ${ }^{11}$ This analysis also showed a significantly lower rate of major bleeding with rivaroxaban than LMWH/VKA (1.0\% vs 1.7\%; HR 0.54; 95\% CI 0.37-0.79; $P=0.002)$. This difference was primarily due to a reduction in intracranial, retroperitoneal, and GI bleeding events. ${ }^{11} \mathrm{~A}$ separate analysis of the EINSTEIN-DVT and EINSTEINPE trials evaluated both the severity upon presentation and clinical course of the major bleeding events. ${ }^{19}$ Major bleeding was defined by the International Society on Thrombosis and 


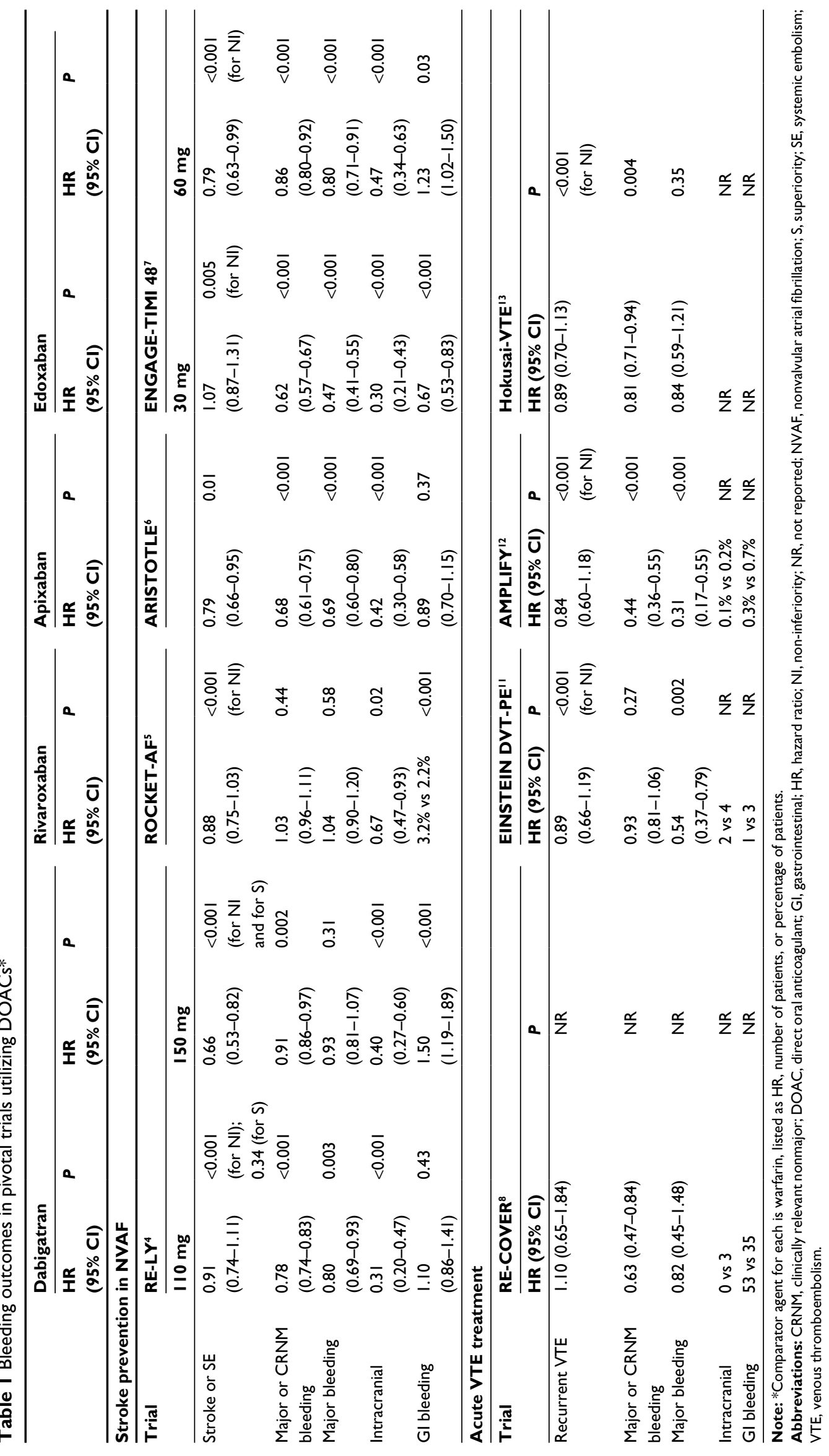


Hemostasis (ISTH) criteria and was further classified on an independent scale including "presentation without urgency" to "need for emergent intervention" or "fatal event." Of major bleeding events that occurred, a less severe presentation was observed more often in patients receiving rivaroxaban than LMWH/VKA (78\% vs 62\%, respectively). Major bleeding events that presented as severe, which required emergent intervention, was classified more often in those receiving LMWH/VKA than in those receiving rivaroxaban $35 \%$ vs $20 \%$, respectively). Bleeding events were also stratified by the clinical course required, from utilizing mild supportive measures to elaborate lifesaving attempts. Interventions considered to be mild occurred more frequently in those receiving rivaroxaban than in those receiving LMWH/VKA ( $76 \%$ vs $67 \%$, respectively). Likewise, $21 \%$ of those patients who bled on LMWH/VKA required immediate or elaborate measures to avoid death compared to $15 \%$ of those receiving rivaroxaban. The authors concluded major bleeding occurred less often with rivaroxaban $(1.0 \%$ vs $1.7 \%$; HR $0.54 ; 95 \%$ CI $0.37-0.79 ; P=0.002)$ and with less severity than with LMWH/VKA therapy. ${ }^{19}$

\section{Apixaban}

Bleeding events from the Apixaban for Reduction in Stroke and Other Thromboembolic Events in Atrial Fibrillation (ARISTOTLE) trial comparing apixaban to warfarin have been evaluated..$^{20}$ Major bleeding occurred in 789 patients (4.3\%) overall after a median of 20.5 months. Of these patients with a documented major hemorrhage, significantly fewer occurred in patients receiving apixaban than warfarin (2.13\% vs 3.09\%; HR 0.69; 95\% CI 0.60-0.80; $P<0.001)$. Major GI bleeding was not significant between groups, but apixaban did have significantly less intracranial bleeding (HR 0.42; 95\% CI 0.30-0.58; $P<0.001$ ). Also significant, death within 30 days of a major bleed occurred half as often with apixaban than with warfarin (HR 0.50; 95\% CI $0.33-0.74 ; P<0.001)$. The authors found that increasing age, prior hemorrhage, prior stroke or transient ischemic attack (TIA), diabetes, lower creatinine clearance $(\mathrm{CrCl})$, and use of aspirin or NSAID independently increased the risk of major bleeding. ${ }^{20}$ Likewise, an analysis of bleeding events from the VTE population enrolled in the Apixaban for the Initial Management of Pulmonary Embolism and Deep-Vein Thrombosis as First-Line Therapy (AMPLIFY) trial has been described. Investigators evaluated the severity of major bleeding and CRNM bleeding upon presentation as well as categorizing the clinical course of the bleed. ${ }^{21}$ Major bleeding events categorized as severe occurred less often with apixaban vs LMWH/VKA therapy but was not statistically significant (28.5\% vs 44.9\%; OR 0.49; $95 \%$ CI 0.14-1.78). Presentation with less severe episodes occurred at a higher frequency in patients treated with apixaban. A severe clinical course was not significantly different in those who bled on apixaban vs LMWH/VKA (14.3\% vs $12.2 \%$; OR 1.19; 95\% CI 0.21-6.69). Presentation and course of CRNM bleeding were similar between the apixaban group and the LMWH/VKA group (25.0\% vs $22.7 \%$; OR 1.13 ; 95\% CI 0.65-1.97). In both groups, the authors found that standard measures (such as interrupting anticoagulation and applying pressure to the site) were sufficient to manage the majority of major bleeding events ( $86 \%$ vs $88 \%$ ). The authors concluded that there was no difference in the clinical presentation and course of CRNM bleeding events between the apixaban and LMWH/VKA groups, but there was a trend toward less severe presentation of major bleeding events in patients treated with apixaban. ${ }^{21}$

\section{Edoxaban}

In the Effective Anticoagulation with Factor Xa Next Generation in Atrial Fibrillation-Thrombolysis in Myocardial Infarction 48 (ENGAGE AF-TIMI 48) trial, the primary safety end point of major bleeding was found to be significantly less $(2.75 \%$ with high-dose HR $0.80 ; 95 \%$ CI $0.71-0.91 ; P<0.001$; vs $1.61 \%$ with low-dose HR $0.47 ; 95 \%$ CI $0.41-0.55 ; P<0.001$; vs $3.43 \%$ with warfarin) in those taking high- or low-dose edoxaban vs those taking warfarin for the prevention of SSE in NVAF. ${ }^{7}$ In the Hokusai-VTE trial, major or CRNM bleeding occurred significantly less often in the edoxaban group than the VKA group $(8.5 \%$ vs $10.3 \%$; HR 0.81 ; 95\% CI $0.71-0.94 ; P=0.004)$. Rates of major bleeding were similar between groups $(1.4 \%$ vs $1.6 \%$; HR $0.84 ; 95 \%$ CI $0.59-1.21 ; P=0.35) .{ }^{13}$ A safety analysis for the major bleeding events in the Hokusai-VTE study described no significant difference in severity or clinical course in major bleeding with edoxaban compared to enoxaparin/warfarin. ${ }^{22}$ Of the major bleeding events in the trial, 54\% related to edoxaban were considered milder at the time of presentation compared to $42 \%$ of bleeding events with VKA, however, not statistically significant. More severe clinical presentation was also numerically less in the edoxaban group (46\%) than the VKA group (58\%) but not statistically significant (OR 0.62; 95\% CI 0.30-1.27; $P=0.19$ ). The clinical course of severe major bleeding events was not considered different between edoxaban and VKA ( $23 \%$ vs $30 \%$ in edoxaban vs VKA, respectively; OR 0.72 ; 95\% CI $0.32-1.66 ; P=0.46)$. The authors concluded that 
major bleeding events with edoxaban in the Hokusai-VTE study had similar presentation and clinical course than those with VKA therapy. However, there was a nonsignificant trend toward milder presentation and course in the edoxaban group. ${ }^{22}$

\section{Overall}

A meta-analysis pooling the results of all four pivotal clinical trials in patients with NVAF (RE-LY, ROCKET AF, ARISTOTLE, and ENGAGE AF-TIMI 48) included 42,411 patients receiving a DOAC and 29,272 patients receiving a VKA. ${ }^{23}$ DOACs had a nonsignificant reduction in rates of major bleeding overall (HR $0.86 ; 95 \%$ CI $0.73-1.00 ; P=0.06$ ) with significant reductions in hemorrhagic stroke (HR 0.49; 95\% CI 0.38-0.64; $P<0.0001)$ and intracranial hemorrhage (HR $0.49 ; 95 \%$ CI $0.39-0.59 ; P<0.0001$ ) compared to VKA. However, the DOACs were associated with an increase in GI bleeding (HR 1.25; 95\% CI 1.01-1.55; $P=0.043$ ). Reduction in major bleeding was driven by significant reductions in the ARISTOTLE and ENGAGE AF-TIMI 48 trials. ${ }^{23}$

The results of the aforementioned studies, some using independently developed bleeding classifications, confirm that major bleeding with a DOAC is less severe in nature and required less intensive management than those with standard VKA therapy. When used in patients with NVAF, GI bleeding is higher than VKA with dabigatran $150 \mathrm{mg}$, rivaroxaban, and edoxaban. An increase in GI bleeding in the treatment of the VTE population has not been appreciated. While randomized comparisons between the DOACs are not available, GI bleeding seems to occur the least in patients receiving apixaban. ${ }^{24}$

\section{Post-marketing bleeding events Food and Drug Administration (FDA) adverse event reporting}

Increased use of the DOACs over recent years has allowed for comparison between clinical trial and real-world bleeding rates. Bleeding outcomes in patients receiving dabigatran, rivaroxaban, and apixaban have been compared to warfarin separately, most confirming trial data, although some studies with dabigatran have shown conflicting outcomes. ${ }^{15,16,25-28}$ Two separate analyses of the FDA Adverse Event Reporting System (FAERS) from 2010 to 2011 showed conflicting results. ${ }^{15,16}$ While both studies are subject to reporting bias, with a possible lower threshold of reporting events related to the newer dabigatran, Southworth et a ${ }^{15}$ found similar bleeding rates associated with dabigatran and warfarin overall, which is consistent with RE-LY, while McConeghy et al ${ }^{16}$ reported a higher proportion of bleeding with dabigatran than warfarin. In the McConeghy et $\mathrm{al}^{16}$ analysis, intracranial bleeding was lower with dabigatran, but rates of GI bleeding were increased than with warfarin, both of which are consistent with RE-LY.

\section{International claims data}

More recently, studies have attempted to compare bleeding rates of DOACs to that of warfarin and among each DOAC using large claims databases (Table 2). Inherent limitations in evaluating claims data include the observational nature of reported data and the inability to identify confounding variables such as over-the-counter aspirin or NSAID use, which could influence bleeding results. Nevertheless, this

Table 2 Bleeding comparisons between DOACs and warfarin from international claims data

\begin{tabular}{|c|c|c|c|c|c|c|}
\hline & $\begin{array}{l}\text { Apixaban vs } \\
\text { warfarin: } \\
\text { HR }(95 \% \mathrm{CI})\end{array}$ & $\begin{array}{l}\text { Rivaroxaban vs } \\
\text { warfarin: } \\
\text { HR }(95 \% \mathrm{Cl})\end{array}$ & $\begin{array}{l}\text { Dabigatran vs } \\
\text { warfarin: } \\
\text { HR }(95 \% \mathrm{Cl})\end{array}$ & $\begin{array}{l}\text { Apixaban vs } \\
\text { rivaroxaban: } \\
\text { HR }(95 \% \mathrm{CI})\end{array}$ & $\begin{array}{l}\text { Apixaban vs } \\
\text { dabigatran: } \\
\text { HR }(95 \% \mathrm{CI})\end{array}$ & $\begin{array}{l}\text { Rivaroxaban vs } \\
\text { dabigatran: } \\
\text { HR }(95 \% \mathrm{Cl})\end{array}$ \\
\hline \multicolumn{7}{|l|}{ Major bleeding } \\
\hline Larsen et $\mathrm{al}^{29}(\mathrm{n}=6 \mathrm{I}, 678)$ & $0.61(0.49-0.75)$ & $1.06(0.91-1.23)$ & $0.58(0.47-0.71)$ & - & - & - \\
\hline Halvorsen et $\mathrm{al}^{30}(\mathrm{n}=32,675)$ & $\begin{array}{l}0.70(0.6 \mathrm{I}-0.80) ; \\
P<0.00 \mathrm{I}\end{array}$ & $\begin{array}{l}I .05(0.94-1.17) ; \\
P=0.400\end{array}$ & $\begin{array}{l}0.74(0.66-0.84) \\
P<0.00 \text { I }\end{array}$ & - & - & - \\
\hline Noseworthy et $\mathrm{al}^{31}(\mathrm{n}=57,788)$ & - & - & - & $\begin{array}{l}0.39(0.28-0.54) \\
P<0.001\end{array}$ & $\begin{array}{l}0.50(0.36-0.70) \\
P<0.001\end{array}$ & $\begin{array}{l}1.30(1.10-1.53) ; \\
P<0.01\end{array}$ \\
\hline Lip et $\mathrm{al}^{32}(\mathrm{n}=45,36 \mathrm{I})$ & $0.53(0.39-0.7 I)$ & $0.98(0.83-1.17)$ & $0.69(0.50-0.96)$ & $\begin{array}{l}\text { I.82 (I.36-2.43) } \\
(\mathrm{R} \text { vs A) }\end{array}$ & $\begin{array}{l}\text { I.4I }(0.93-2.14) \\
(D \text { vs } A)\end{array}$ & $\begin{array}{l}\text { I.05 (0.74-I.49) } \\
\text { (D vs R) }\end{array}$ \\
\hline \multicolumn{7}{|l|}{ Intracranial bleeding } \\
\hline Larsen et $\mathrm{al}^{29}(\mathrm{n}=6 \mathrm{I}, 678)$ & $0.72(0.42-1.24)$ & $0.56(0.34-0.90)$ & $0.40(0.25-0.65)$ & - & - & - \\
\hline Halvorsen et $\mathrm{al}^{30}(\mathrm{n}=32,675)$ & $\begin{array}{l}0.56(0.36-0.86) ; \\
P=0.009\end{array}$ & $\begin{array}{l}0.93(0.67-1.29) \\
P=0.656\end{array}$ & $\begin{array}{l}0.46(0.30-0.70) \\
P<0.00 \text { I }\end{array}$ & - & - & - \\
\hline Noseworthy et $\mathrm{al}^{31}(\mathrm{n}=57,788)$ & - & - & - & $\begin{array}{l}0.56(0.21-1.45) ; \\
P=0.23\end{array}$ & $\begin{array}{l}0.65(0.25-1.65) \\
P=0.36\end{array}$ & $\begin{array}{l}1.79(1.12-2.86) ; \\
P=0.02\end{array}$ \\
\hline
\end{tabular}

Abbreviations: A, apixaban; D, dabigatran; DOAC, direct oral anticoagulants; HR, hazard ratio; $R$, rivaroxaban. 
type of data allows comparison of real-world outcomes with those previously reported in randomized controlled settings.

Using data from three national Danish databases over a period of 4 years between 2011 and 2015, Larsen et $\mathrm{al}^{29}$ compared the efficacy and safety between newly initiated standard-dose dabigatran, rivaroxaban, and apixaban compared to dose-adjusted warfarin in patients with NVAF. Of the 61,678 patients included in the study, $57 \%$ of patients were on warfarin, $21 \%$ on dabigatran, $12 \%$ on rivaroxaban, and $10 \%$ on apixaban. With an average follow-up of 1.9 years (0.9 years for apixaban), results showed a significantly lower rate of major bleeding with apixaban (HR 0.61; 95\% CI 0.49-0.75) and dabigatran (HR 0.58; 95\% CI 0.47-0.71) compared to warfarin. Major bleeding rates from rivaroxaban were not different compared to those from warfarin (HR 1.06; 95\% CI 0.91-1.23). Intracranial bleeding was significantly less with dabigatran (HR $0.40 ; 95 \%$ CI $0.25-0.65$ ) and rivaroxaban (HR 0.56; 95\% CI 0.34-0.90) compared to warfarin. Apixaban was similar to warfarin (HR 0.72; 95\% CI 0.42-1.24) with regard to rates of intracranial bleeding. This differs from clinical trials in which apixaban showed a significant reduction in intracranial bleeding, but may be explained by the smaller number of events and shorter follow-up in the apixaban group in this trial given the later approval date. ${ }^{29}$

The Norwegian Patient Registry and Norwegian Prescription Database were used to evaluate patients with NVAF receiving an initial prescription for warfarin or a DOAC between January 2013 and June $2015 .{ }^{30}$ Of the 32,675 patients identified, $35 \%$ received warfarin, $24 \%$ received dabigatran, $21 \%$ received rivaroxaban, and $20 \%$ received apixaban. With Cox proportional hazards adjusted for baseline characteristics, apixaban (HR 0.70; 95\% CI 0.61-0.80; $P<0.001)$, and dabigatran (HR 0.74; 95\% CI 0.66-0.84; $P<0.001$ ) were associated with lower rates of major bleeding. Rates of major bleeding with rivaroxaban were similar to warfarin (HR 1.05; 95\% CI 0.94-1.17; $P=0.400)$. These associations were also true when reduced doses of each DOAC were evaluated. Rates of GI bleeding were significantly higher than warfarin with both dabigatran (HR 1.26; 95\% CI 1.01-1.57; $P=0.037$ ) and rivaroxaban (HR 1.37; 95\% CI 1.12-1.69; $P=0.003$ ). There was no significant difference in the rate of GI bleeding between warfarin and apixaban (HR 0.77; 95\% CI 0.59-1.02; $P=0.068)$. Regarding rates of intracranial bleeding, dabigatran (HR 0.46; 95\% CI 0.30-0.70; $P<0.001)$ and apixaban (HR 0.56; 95\% CI 0.36-0.86; $P=0.009$ ) showed significantly lower rates than warfarin. There was no significant difference between rivaroxaban and warfarin (HR 0.93; 95\%
CI $0.67-1.29 ; P=0.656)$. The results of this study reflected similar trends as those seen in the Danish study as well as major clinical trials. ${ }^{30}$

A study using administrative claims data from Optum Labs Data Warehouse, which included privately insured and Medicare Advantage individuals throughout the United States, compared three separate one-to-one propensityscore-matched cohorts to evaluate bleeding rates between rivaroxaban and dabigatran $(\mathrm{n}=31,574)$, apixaban and dabigatran $(n=13,084)$, and apixaban and rivaroxaban $(n=13,130)$ in patients with NVAF. ${ }^{31}$ The study included adults with 12 months of continuous enrollment between 2010 and 2015 and matched patients based on baseline characteristics, comorbidities, and prior warfarin use. Compared to dabigatran, rivaroxaban showed a higher risk of major bleeding (HR 1.30; 95\% CI 1.10-1.53; $P<0.01$ ) and intracranial bleeding (HR 1.79; 95\% CI 1.12-2.86; $P=0.02$ ). Compared to dabigatran, apixaban had lower rates of major bleeding (HR 0.50; 95\% CI 0.36-0.70; $P<0.001$ ) and similar rates of intracranial bleeding (HR 0.65; 95\% CI 0.25-1.65; $P=0.36$ ). Compared to rivaroxaban, apixaban showed lower rates of major bleeding (HR 0.39; 95\% CI 0.28-0.54; $P<0.001$ ) and had similar rates of intracranial bleeding (HR 0.56; 95\% CI $0.21-1.45 ; P=0.23$ ). While there is inherent limitation in interpreting such differences outside of a randomized comparison, the authors concluded that when comparing dabigatran, rivaroxaban, and apixaban, apixaban was associated with lower risk and rivaroxaban was associated with higher risk of bleeding. ${ }^{31}$

A separate observational study utilizing the Optum Labs Data Warehouse reported rates of GI bleeding, both upper and lower, in patients newly initiated on dabigatran, rivaroxaban, and warfarin from 2010 to 2013 using propensity matching. Patients were classified as either NVAF or non-atrial fibrillation (AF), and patients with mechanical heart valves or mitral stenosis were excluded. ${ }^{24}$ In NVAF patients, the DOACs had lower rates of GI bleeding than warfarin although the differences were not significant with both dabigatran (HR 0.79; 95\% CI 0.61-1.03) and rivaroxaban (HR 0.93; 95\% CI 0.691.25). In non-AF patients, GI bleeding was similar compared to warfarin with dabigatran (HR 1.14; 95\% CI 0.54-2.39) and rivaroxaban (HR $0.89 ; 95 \% \mathrm{CI} 0.60-1.32) .{ }^{24}$ The authors suggested that there is no major concern for increased GI bleeding with the DOACs but did report increased rates of GI bleeding in those patients aged $>75$ years.

Data from the Truven MarketScan ${ }^{\circledR}$ Commercial \& Medicare supplemental US claims database from 2012 to 2014 were utilized to evaluate bleeding rates of the DOACs in comparison 
to warfarin as well as each other. ${ }^{32}$ A total of 45,361 patients were newly anticoagulated for NVAF with warfarin (34.1\%), apixaban (16.4\%), rivaroxaban $(39.2 \%)$, and dabigatran (10.3\%). Compared to those initiated on warfarin, there was a significant reduction in the rate of major bleeding with those initiated on apixaban (HR 0.53 ; 95\% CI $0.39-0.71$ ) and dabigatran (HR 0.69; 95\% CI 0.50-0.96). Rivaroxaban showed similar rates of major bleeding compared to warfarin (HR 0.98; 95\% CI 0.83-1.17). In this analysis, dabigatran showed less overall bleeding than warfarin; however, 10.6\% of dabigatran patients were prescribed the lower $75 \mathrm{mg}$ dose. In the dabigatran $150 \mathrm{mg}$ group, there was a similar rate of major bleeding compared to warfarin (HR 0.71; 95\% CI 0.49-1.05). These results aligned with those from the major clinical trials in NVAF. ${ }^{4-6}$ When comparing the DOACs to each other, rivaroxaban patients had a significantly higher risk of major bleeding than the apixaban patients (HR 1.82; 95\% CI 1.36-2.43). There were no significant differences in major bleeding rates between apixaban and dabigatran (HR 1.41; 95\% CI 0.93-2.14) and between dabigatran and rivaroxaban (HR 1.05; 95\% CI 0.74-1.49). However, when comparing patients taking dabigatran $150 \mathrm{mg}$ to those taking rivaroxaban $20 \mathrm{mg}$, a significantly higher risk of major bleeding was seen with rivaroxaban (HR 1.65; 95\% CI 1.15-2.36). ${ }^{32}$

Finally, rates of bleeding-related hospital readmissions of patients discharged on apixaban (5.5\%), dabigatran (43.9\%), or rivaroxaban $(50.5 \%)$ for newly diagnosed NVAF were analyzed among patients enrolled in Premier and Cerner Health Facts databases. Both databases showed a significant increase in readmissions with patients on rivaroxaban compared to apixaban but showed similar rates with patients on dabigatran compared to apixaban. Rivaroxaban was not directly compared to dabigatran in this analysis. ${ }^{33}$

As with any observational data, despite best efforts to match patients and control for confounders, these results are subject to inherent limitations including selection bias and lack of laboratory data such as renal function to confirm correct dosing of the DOACs. For the warfarin patients, time in therapeutic range (TTR) has been shown to be integral in making comparisons with the DOACs and is unavailable when using claims-based data. There are also less data available for bleeding rates in apixaban as well as edoxaban based on the timing of approval in the United States and many other countries. Nonetheless, available data have suggested similar rates of overall bleeding in the DOACs compared to the original clinical trials, the exception being one study which showed similar rates of intracranial bleeding between apixaban and warfarin. The authors of this study suggested that this finding may be due to low event rates based on the more recent approval of apixaban. ${ }^{29}$ Future investigations will likely be published as the number of patients on apixaban and edoxaban increase.

\section{Global registry data}

In addition to health claims data, national and global registries have been implemented to continue pharmacovigilance with oral anticoagulation. The Global Anticoagulant Registry in the Field - Atrial Fibrillation (GARFIELD-AF) is a global registry, which enrolled its first patient in 2009 and has recently completed recruitment of over 57,000 patients with newly diagnosed NVAF. Published outcomes from the first 2 years of patient follow-up indicate that a total of 17,162 patients were enrolled from over 800 practice sites in over 30 countries. $^{34}$ Of the $60.8 \%$ of patients given anticoagulant therapy, half were started on warfarin and $10.8 \%$ were started on a DOAC. A total of $27.4 \%$ of patients were started on antiplatelet therapy only and $11.8 \%$ were not started on anticoagulant or antiplatelet therapy. The rate of first major bleeding was 0.70 per 100 person-years (95\% CI 0.62-0.81) and rates were significantly higher within the first 4 months and significantly decreased beyond this $(P=0.001)$, possibly due to better control of anticoagulation, especially in patients taking warfarin. GI bleeding was the most common site of bleeding and occurred in $1.47 \%$ of the total population. Intracranial bleeding occurred in $0.22 \%$ of the total population. This registry has yet to publish data comparing specific DOACs against each other or warfarin. ${ }^{34}$

The Global Registry on Long-Term Oral Antithrombotic Treatment in Patients with Atrial Fibrillation (GLORIA-AF) is collecting data from up to 2,000 sites in nearly 50 countries on the safety and efficacy of each antithrombotic agent in patients newly diagnosed with NVAF ${ }^{14}$ The registry is also collecting data for patients taking aspirin as well as those not receiving any treatment. The first clinical outcomes from Phase II were recently presented at the 2017 American College of Cardiology annual meeting and demonstrated that, over a 2-year follow-up in 2,937 patients, the rate of major bleeding per 100 patient-years was 1.00 and 1.16 in those receiving dabigatran $150 \mathrm{mg}$ and $110 \mathrm{mg}$, respectively. ${ }^{35}$ Results of the other anticoagulants have yet to be published.

The Dresden NOAC registry is a large registry in Germany recruiting patients newly initiated on a DOAC for NVAF or VTE treatment and has published data for dabigatran and rivaroxaban use for stroke prevention in NVAF. Of the 341 patients on dabigatran, the annualized rate of major bleeding was $2.3 / 100$ (95\% CI 1.14-4.42). Event rates 
were the highest within the first 6 months of initiation and dropped drastically following this time. In contrast to the RE-LY trial, annualized bleeding rates were higher for the dabigatran $110 \mathrm{mg}$ group (2.9/100 patient-years) than for the dabigatran $150 \mathrm{mg}$ group (1.7/100 patient-years), which the authors attributed to selection bias as patients with a higher inherent bleeding risk would likely be initiated on the lower dose. While the authors caution against direct comparison to clinical trials, they conclude that real-world use is not worse than that reported in the original RE-LY trial. ${ }^{36}$ Within the same time period, 1,204 patients received rivaroxaban and showed an annualized bleeding rate of 3.0/100 patient-years (95\% CI 2.3-3.8). Similar to real-world data with dabigatran, those receiving the reduced dose of rivaroxaban $15 \mathrm{mg}$ had higher rates of bleeding than the $20 \mathrm{mg}$ dose (4.5 vs 2.4/100 patient-years). While patients on the lower dose had higher rates of renal dysfunction, they were also older, had more comorbidities and higher HAS-BLED (Hypertension, Abnormal Renal/Liver Function, Stroke, Bleeding History or Predisposition, Labile International Normalized Ratio, Elderly, Drugs/Alcohol) scores. The authors noted that annualized major bleeding rates were numerically less than those in the ROCKET AF trial (3.6/100 patient-years) and concluded that daily use of rivaroxaban is not worse than what has been published in clinical trials. ${ }^{37}$

Xarelto ${ }^{\circledR}$ for Prevention of Stroke in Patients with Atrial Fibrillation (XANTUS) is a prospective international registry initiated by Bayer HealthCare for patients newly initiated on rivaroxaban in Europe, Canada, and Israel. ${ }^{38}$ Of the 6,784 patients started on rivaroxaban, the annualized rate of major bleeding was reported as $2.1 / 100$ patient-years $(95 \%$ CI 1.8-2.5). The rates of intracranial hemorrhage and GI bleeding were $0.4 / 100$ patient-years (95\% CI $0.3-0.6)$ and $0.9 / 100$ patient-years (95\% CI 0.6-1.1), respectively. Authors concluded that rates of bleeding occurred less than those seen in the ROCKET AF trial (3.6/100 patient-years), but a less restrictive definition of bleeding was used. Incidence of intracranial hemorrhage was similar to the ROCKET AF trial (0.5/100 patient-years), and GI bleeding rates were lower (2.0/100 patient-years). The authors concluded that overall rates of bleeding with rivaroxaban in a real-world setting were generally low and not worse than those reported in the ROCKET AF trial. ${ }^{38}$

Additional ongoing registries are summarized in Table 3. Now that treatment guidelines recognize the DOACs as first line therapies, the quantity and availability of real world experience with these agents will increase, enabling clinicians to make more informed decisions when initiating anticoagulation with the agents. ${ }^{1}$

\section{Benefit-risk assessment Proper patient selection}

Careful patient selection should be considered to mitigate the potential risk of bleeding when anticoagulation with a DOAC is desired. Insight from randomized data suggest that age, renal function, prior history of stroke, TIA, or hemorrhage, and use of antiplatelet or anti-inflammatory agents increase the risk of major bleeding with these agents. Certain patient populations were excluded from VTE and NVAF clinical trials, and avoiding use in patients with these characteristics is prudent to circumvent inherent risk. Further, dosing was adjusted based upon estimated $\mathrm{CrCl}$ and/or the presence of drug interactions, all which could affect safety and efficacy outcomes. The following conditions should be considered according to evidence-based and pharmacokinetic data to achieve full pharmacotherapeutic benefit of the DOACs while avoiding potential risks for bleeding.

\section{Renal impairment}

The most important factor when considering DOAC therapy is renal function. Whereas warfarin is not affected by renal impairment, each of the DOACs to a varying degree is eliminated by the kidney (Table 4). Moderate to severe renal impairment will increase the risk for bleeding as serum drug concentrations can accumulate, affecting dabigatran the most and apixaban in the least. ${ }^{2,3}$

FDA package labeling has provided dosing recommendations based on estimated $\mathrm{CrCl}$. However, some ambiguity exists with how to renally adjust dosing, since all pivotal VTE clinical trials excluded patients with a $\mathrm{CrCl}$ of <25-30 mL/min. ${ }^{8-10,12,13}$ Trials in NVAF also excluded patients with $\mathrm{CrCl}<30 \mathrm{~mL} / \mathrm{min}$, with the exception of apixaban where renal function was considered in addition to older age and low body weight to be of concern. ${ }^{4-7}$ Dabigatran is $80 \%$ renally eliminated via glomerular filtration; RE-LY and RECOVER clinical trials excluded patients with an estimated $\mathrm{CrCl}$ of $<30 \mathrm{~mL} / \mathrm{min}$. The FDA includes renal adjustment of dabigatran in its package labeling to $75 \mathrm{mg}$ twice daily in patients with a $\mathrm{CrCl}$ of $15-30 \mathrm{~mL} / \mathrm{min}$; however, importantly this dosing was not studied in either RE-LY or RECOVER. ${ }^{4,8,39}$ The rationale for this dosing recommendation is largely derived from pharmacokinetic simulation and modeling. ${ }^{40,41}$ Since there is a lack of in vivo 
Table 3 Global registries of DOACs used for the treatment of VTE and prevention of SSE in NVAF

\begin{tabular}{|c|c|c|c|c|c|c|}
\hline Name & Dates and location & Indication & Drug(s) & $\begin{array}{l}\text { Target } \\
\text { recruitment }\end{array}$ & $\begin{array}{l}\text { National clinical } \\
\text { trial identifier(s) }\end{array}$ & Outcomes \\
\hline GARFIELD-AF & $\begin{array}{l}\text { December } 2009 \text {-July } \\
2018 ; 35 \text { countries }\end{array}$ & $\begin{array}{l}\text { Newly diagnosed } \\
\text { NVAF }\end{array}$ & $\begin{array}{l}\text { Warfarin; } \\
\text { DOAC; } \\
\text { antiplatelet; } \\
\text { no therapy }\end{array}$ & 55,000 & NCT0I090362 & $\begin{array}{l}\text { Characterize treatment patterns } \\
\text { and outcomes; rates of stroke } \\
\text { and bleeding }\end{array}$ \\
\hline GARFIELD-VTE & $\begin{array}{l}\text { March 20I4- } \\
\text { December 20I8; } 20 \\
\text { countries }\end{array}$ & $\begin{array}{l}\text { Acute, subacute, } \\
\text { and extended } \\
\text { duration VTE }\end{array}$ & $\begin{array}{l}\text { Warfarin; } \\
\text { DOAC }\end{array}$ & 10,000 & NCT02I5549I & $\begin{array}{l}\text { Rate of recurrent VTE; bleeding } \\
\text { events }\end{array}$ \\
\hline GLORIA-AF & $\begin{array}{l}\text { May 20II-January } \\
2020 ; 50 \text { countries }\end{array}$ & $\begin{array}{l}\text { Newly diagnosed } \\
\text { NVAF }\end{array}$ & $\begin{array}{l}\text { Warfarin; } \\
\text { DOAC; } \\
\text { antiplatelet; } \\
\text { no therapy }\end{array}$ & 56,000 & $\begin{array}{l}\text { Phase I: } \\
\text { NCTOI428765; } \\
\text { Phase II/III: } \\
\text { NCTOI937377, } \\
\text { NCTOI46870I, } \\
\text { NCTOI67I007 }\end{array}$ & $\begin{array}{l}\text { Characterize treatment patterns } \\
\text { and outcomes; rates of stroke } \\
\text { and bleeding }\end{array}$ \\
\hline $\begin{array}{l}\text { Dresden NOAC } \\
\text { registry }\end{array}$ & $\begin{array}{l}\text { November 2011- } \\
\text { December 2018; } \\
\text { Germany }\end{array}$ & $\begin{array}{l}\text { Newly diagnosed } \\
\text { NVAF or VTE }\end{array}$ & $\begin{array}{l}\text { Warfarin; } \\
\text { DOAC }\end{array}$ & 3,500 & NCT0I588II9 & $\begin{array}{l}\text { Characterize treatment patterns } \\
\text { and outcomes; rates of stroke } \\
\text { and bleeding }\end{array}$ \\
\hline ORBIT-AF II & $\begin{array}{l}\text { February 2013- } \\
\text { February 2018; United } \\
\text { States }\end{array}$ & $\begin{array}{l}\text { Newly diagnosed } \\
\text { NVAF or recent } \\
\text { transition to } \\
\text { DOAC }\end{array}$ & DOAC & 15,000 & NCT0I70I8I7 & Major bleeding \\
\hline $\begin{array}{l}\text { RE-COVERY } \\
\text { DVT/PE }\end{array}$ & $\begin{array}{l}\text { November 2015- } \\
\text { December 2018; } \\
\text { multinational }\end{array}$ & $\begin{array}{l}\text { Newly diagnosed } \\
\text { DVT and/or PE }\end{array}$ & $\begin{array}{l}\text { Dabigatran; } \\
\text { warfarin }\end{array}$ & 14,000 & NCT02596230 & $\begin{array}{l}\text { Characterize DVT/PE patient } \\
\text { population; safety and efficacy of } \\
\text { dabigatran etexilate compared to } \\
\text { VKA regimens }\end{array}$ \\
\hline XANTUS & $\begin{array}{l}\text { June 20I2-March } \\
\text { 20I5; Canada, Europe, } \\
\text { Israel }\end{array}$ & NVAF & Rivaroxaban & 6,784 & NCT0I606995 & $\begin{array}{l}\text { Major bleeding; all-cause } \\
\text { mortality; thromboembolic } \\
\text { events; prescribing } \\
\text { characteristics }\end{array}$ \\
\hline XANTUS-EL & $\begin{array}{l}\text { January 20I3-June } \\
\text { 20I6; Eastern Europe, } \\
\text { Middle East Africa }\end{array}$ & NVAF & Rivaroxaban & 2,101 & NCT0I800006 & $\begin{array}{l}\text { Major bleeding; all-cause } \\
\text { mortality; thromboembolic } \\
\text { events; prescribing } \\
\text { characteristics }\end{array}$ \\
\hline
\end{tabular}

Abbreviations: DOAC, direct oral anticoagulant; DVT, deep vein thrombosis; GARFIELD-AF, Global Anticoagulant Registry in the Field - Atrial Fibrillation; GARFIELDVTE, Global Anticoagulant Registry in the Field - Venous Thromboembolic Events; GLORIA-AF, Global Registry on Long-Term Oral Antithrombotic Treatment in Patients with Atrial Fibrillation; NOAC, novel oral anticoagulant; NVAF, nonvalvular atrial fibrillation; ORBIT-AF II, Outcomes Registry for Better Informed Treatment of Atrial Fibrillation II; PE, pulmonary embolism; RE-COVERY DVT/PE, Global Study on Treatment Secondary Prevention of Acute Venous Thromboembolism; SSE, stroke and systemic embolism; VKA, vitamin K antagonist; VTE, venous thromboembolism; XANTUS, Xarelto ${ }^{\circledR}$ for Prevention of Stroke in Patients with Atrial Fibrillation; XANTUS-EL, Xarelto ${ }^{\circledR}$ for Prevention of Stroke in Patients with Atrial Fibrillation in Latin America and EMEA (Eastern Europe, Middle East, Africa) Region.

trials using $75 \mathrm{mg}$ twice daily in patients with a $\mathrm{CrCl}$ of 15-30 $\mathrm{mL} / \mathrm{min}$, caution should be used when considering dabigatran for patients with this criteria.

Rivaroxaban and edoxaban are approximately 36-50\% renally eliminated. ${ }^{42,43}$ The majority of patients enrolled in the EINSTEIN trials had a $\mathrm{CrCl}>80 \mathrm{~mL} / \mathrm{min}$ and the median $\mathrm{CrCl}$ was $67 \mathrm{~mL} / \mathrm{min}$ in the ROCKET AF trial. ${ }^{5,9,10}$ In the ROCKET AF trial, the rivaroxaban dose was preemptively reduced from $20 \mathrm{mg}$ daily to $15 \mathrm{mg}$ daily in patients with an estimated $\mathrm{CrCl}$ of $30-49 \mathrm{~mL} / \mathrm{min}$, yet package insert labeling for NVAF recommends this dose down to a $\mathrm{CrCl}$ of $15 \mathrm{~mL} / \mathrm{min}^{5,42}$ The majority of patients enrolled in ENGAGE AF-TIMI 48 and Hokusai-VTE had a $\mathrm{CrCl}$ of $>50 \mathrm{~mL} / \mathrm{min}^{7,13}$ FDA labeling for edoxaban includes a $50 \%$ dose reduction to $30 \mathrm{mg}$ daily for patients with $\mathrm{CrCl}$ of $15-50 \mathrm{~mL} / \mathrm{min}$ for either VTE or NVAF indication. ${ }^{43}$

Apixaban is the DOAC that is affected the least by renal impairment $(-25 \%$ of the active drug is cleared by the kidney). The VTE study, AMPLIFY, required no dose adjustment of apixaban in renal impairment but excluded patients with either an serum creatinine $(\mathrm{SCr})>2.5 \mathrm{mg} / \mathrm{dL}$ or $\mathrm{CrCl}<25 \mathrm{~mL} / \mathrm{min}$. However, a dosage reduction from $5 \mathrm{mg}$ to $2.5 \mathrm{mg}$ twice daily was recommended in ARISTOTLE if patients had $\mathrm{SCr} \geq 1.5 \mathrm{mg} / \mathrm{dL}$ along with at least one other increased risk factor for bleeding, specifically age $\geq 80$ years or weight $\leq 60 \mathrm{~kg}$. The majority of patients enrolled in ARISTOTLE and AMPLIFY had $\mathrm{CrCl}>50 \mathrm{~mL} / \mathrm{min}$ and $80 \mathrm{~mL} / \mathrm{min}$, respectively. ${ }^{6,12}$ 


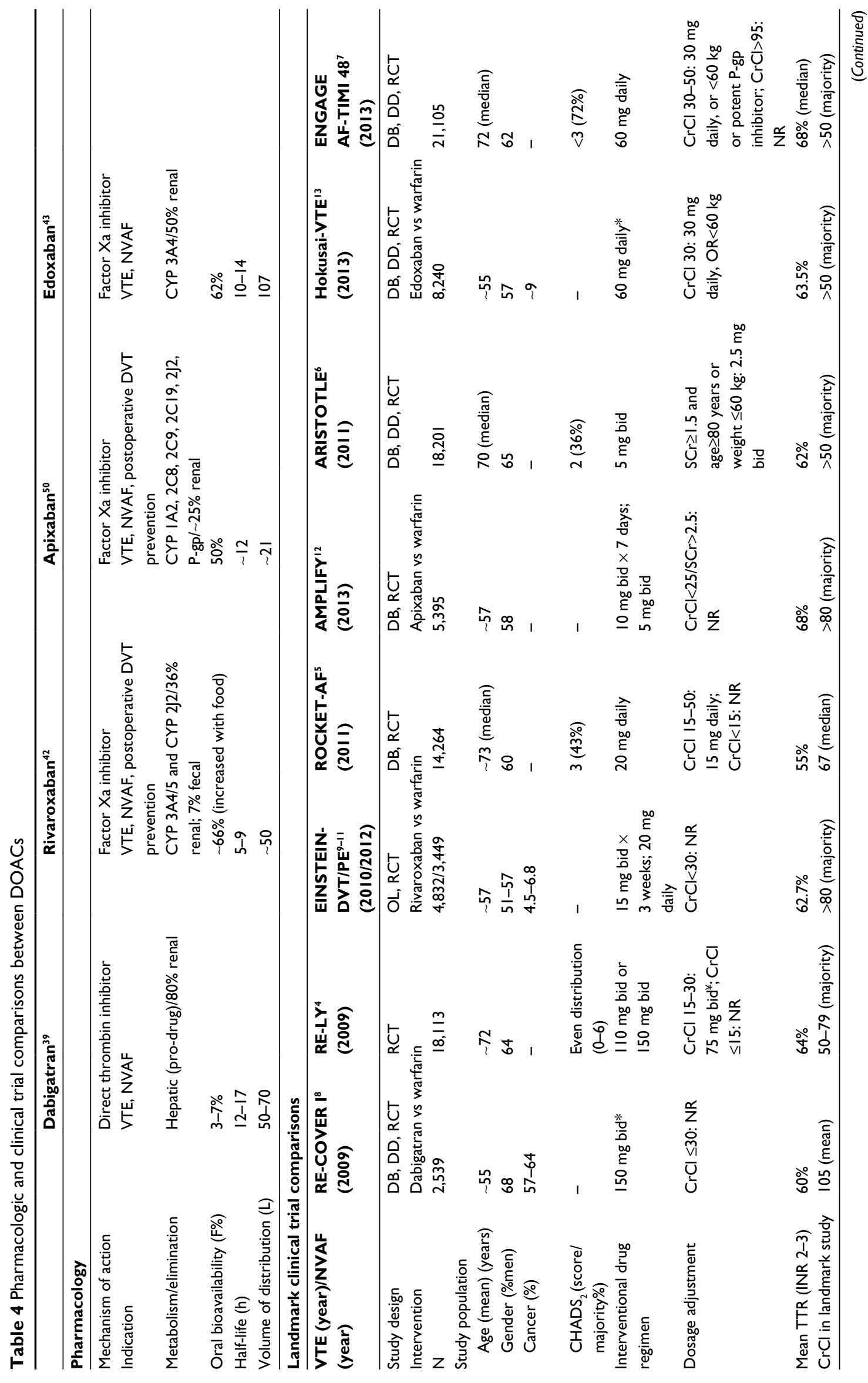




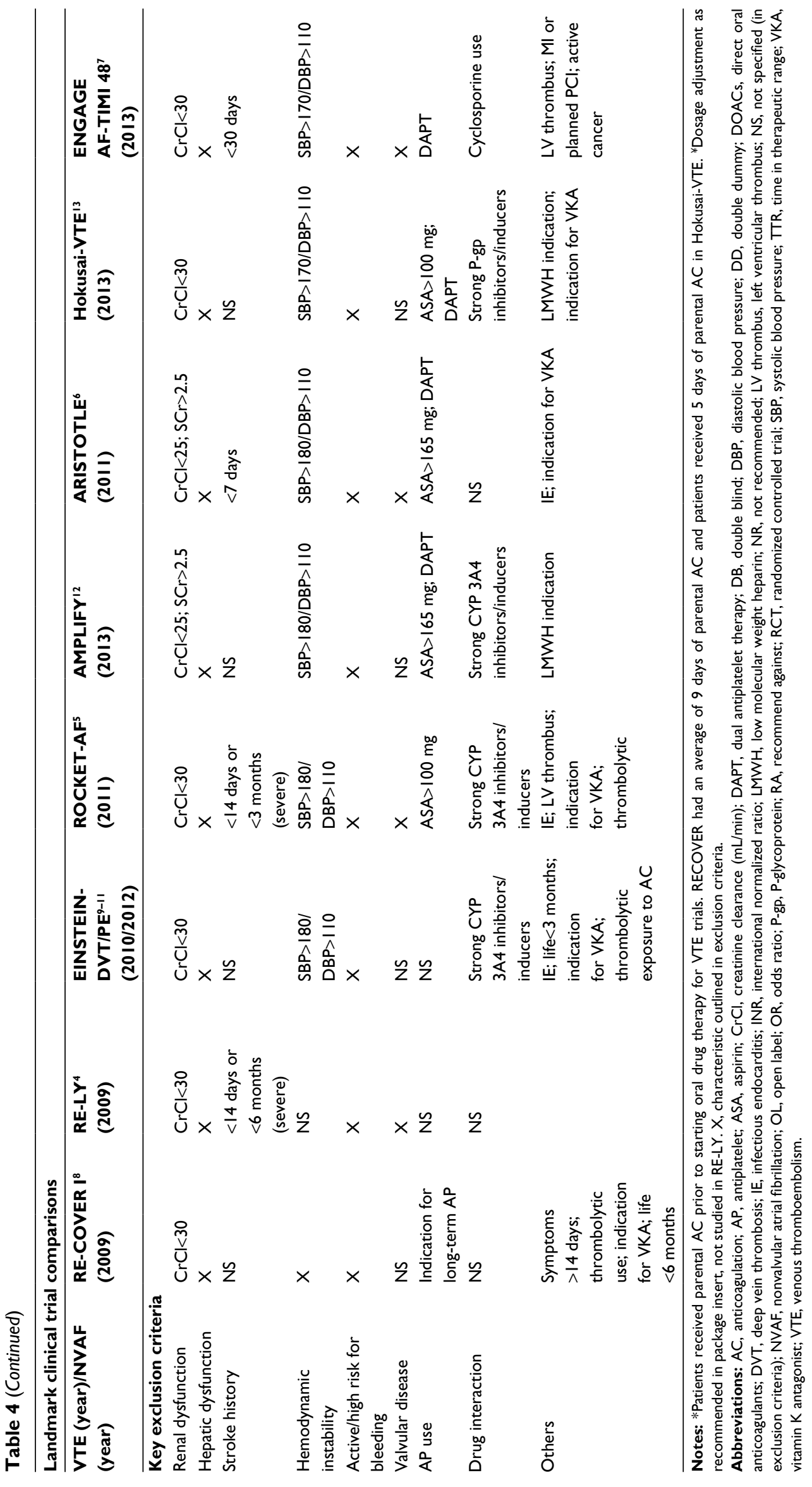


While renal function can reduce the clearance of the oral anticoagulants and therefore increase the risk for bleeding, it should also be noted that enhanced renal function may also expedite clearance, as in the case of edoxaban. This agent is not recommended in patients with atrial fibrillation and an estimated $\mathrm{CrCl}$ of $>95 \mathrm{~mL} / \mathrm{min}$ because of decreased efficacy concerns. ${ }^{7,43}$

Laboratory measurement of serum creatinine and estimation of $\mathrm{CrCl}$ should be established upon initiation of a DOAC prescription and periodically thereafter, especially at times of suspected change in renal function. ${ }^{2,3}$ Careful consideration should be given in situations when renal function falls outside of the average population studied within each individual trial. Atrial fibrillation guidelines in the United States currently recommend warfarin as the agent of choice in patients with severe renal dysfunction or end-stage renal disease. ${ }^{3}$

\section{Elderly}

Age-related changes such as low body mass index (BMI), reduced muscle mass, and changes in glomerular filtration rate have the potential to alter pharmacokinetic response of anticoagulants, leading to an increased risk for bleeding. ${ }^{44}$ In addition, the elderly more commonly have comorbid conditions that require concomitant medication use and drug interactions can influence risk. ${ }^{45}$

Underuse of anticoagulants in NVAF is commonly due to the concern for bleeding potential. ${ }^{45}$ Rates of major hemorrhage in elderly patients with NVAF initiated on warfarin for the prevention of stroke are higher in those aged $\geq 80$ years and are highest within the first 90 days of therapy initiation. ${ }^{46}$ Therefore, patients who were at the highest risk of thromboembolism (i.e., advanced age) also experience most of the bleeding events, which complicates the decision to start anticoagulation therapy in elderly patients. ${ }^{1-3}$ This is also seen with DOACs: $40 \%(n=7,258)$ of patients enrolled in the RE-LY trial were over the age of 70 years. Subgroup comparisons between the younger ( $<75$ years old) and older ( $\geq 75$ years old) patient groups showed higher event and bleeding rates in the older cohort. ${ }^{45}$ Interestingly, comparing dabigatran and warfarin, the point estimates for the HRs for bleeding were higher for both doses of dabigatran than for warfarin, indicating that the incidence of bleeding with dabigatran may be of higher concern than warfarin in those aged $>70$ years.$^{45}$ Similarly, in a prespecified analysis of 6,299 elderly patients enrolled in ROCKET AF, higher events and bleeding rates occurred in the elderly compared to younger patients; however, importantly, there was no increase in major bleeding among those aged 75 years or older receiving rivaroxaban compared to warfarin ( $4.86 \%$ vs $4.4 \%$; $95 \% \mathrm{CI}$ $0.92-1.35)$, thereby indicating that rivaroxaban may pose no greater risk when used in the elderly ${ }^{47}$

Most patients enrolled in the DOAC pivotal trials for NVAF were 70-73 years old, and 55-58 years old in the VTE treatment trials; therefore, safety data on DOAC use in those aged $\geq 75$ years are limited. ${ }^{4-10,12,13} \mathrm{~A}$ meta-analysis including 10 randomized control trials representing 25,031 elderly adults ( $\geq 75$ years) compared dabigatran, rivaroxaban, and apixaban to warfarin for the prevention of SSE in patients with NVAF and treatment of VTE. ${ }^{48}$ Use of these agents in the elderly did not increase clinically relevant bleeding compared to conventional therapy $(6.4 \%$ bleeding with DOAC vs $6.3 \%$ with warfarin; OR $1.02 ; 95 \%$ CI $0.73-1.43)$. The risk for bleeding of the individual agents was also evaluated, noting no increase in elderly patients receiving rivaroxaban (4.5\% vs $4.5 \%$; OR $1.18 ; 95 \%$ CI $0.64-2.19)$ or apixaban (5.1 vs $7.3 \%$; OR $0.80 ; 95 \%$ CI $0.43-1.51)$. The authors noted that safety data were limited with dabigatran due to the lack of reported bleeding outcomes in the elderly subgroup, yet reported similar major or CRNM bleeding between dabigatran and warfarin (9.3\% vs $8.7 \%$; OR 1.07 ; 95\% CI $0.90-1.28) .{ }^{48}$ Efficacy outcomes were better in those elderly patients receiving DOACs compared to warfarin in both indications.

The primary safety outcome of major bleeding in 31,418 patients $\geq 75$ years was evaluated in another meta-analysis including 19 randomized trials $(102,479$ patients total $)$ utilizing all four DOACs. ${ }^{49}$ Bleeding patterns were distinct in the elderly and varied based upon bleed definition and location. Overall, significant reductions in the primary safety outcome of major bleeding in those $\geq 75$ years were seen if the anticoagulant was apixaban (OR $0.63 ; 95 \%$ CI 0.51-0.77; $P<0.0001$ ) or edoxaban (both $30 \mathrm{mg}$ [OR 0.46 ; 95\% CI $0.38-0.57 ; P<0.0001$ ] and $60 \mathrm{mg}$ [OR $0.81 ; 95 \%$ CI $0.67-0.98 ; P=0.003$ ] doses) compared to warfarin. A nonsignificant higher risk of major bleeding in the elderly was seen with dabigatran $150 \mathrm{mg}$ twice daily (OR 1.18; 95\% CI $0.97-1.44 ; P=0.10)$ compared to warfarin. This was in contrast to evaluation of the total population (all ages) where major bleeding was similar with dabigatran $150 \mathrm{mg}$ than VKA and significantly lower with the $110 \mathrm{mg}$ dose. No significant difference in bleeding rates was seen in the elderly when comparing rivaroxaban and warfarin. ${ }^{49}$ Secondary bleeding outcomes also included differences in clinically relevant, GI, intracranial, and fatal bleeding but should be interpreted with caution given the limited numbers of event rates in this older population. In the total population, all DOACs except rivaroxaban and dabigatran $110 \mathrm{mg}$ demonstrated superior 
reductions in clinically relevant bleeding outcomes, whereas, in the elderly population, only apixaban showed superiority to VKA (OR 0.64; 95\% CI 0.54-0.76; $P<0.0001$ ). GI bleeding was higher than VKA with dabigatran $150 \mathrm{mg}$, rivaroxaban, and edoxaban $60 \mathrm{mg}$ in the total population; but significantly higher with only both doses of dabigatran in the elderly (150 mg: OR 1.78; 95\% CI 1.35-2.35; $P<0.0001 ; 110 \mathrm{mg}$ : OR 1.40; 95\% CI 1.04-1.90; $P=0.03$ ). Data on GI bleeding in the elderly for the other DOACs were not reported. Intracranial hemorrhage was lower with all DOACs compared to VKA in the total population, but only significantly lower in the elderly with both doses of dabigatran (150 mg: OR 0.43 ; 95\% CI $0.26-0.72 ; P=0.001 ; 110 \mathrm{mg}$ : OR $0.36 ; 95 \%$ CI $0.22-0.61 ; P=0.0001)$ and apixaban (OR $0.38 ; 95 \%$ CI $0.24-0.59 ; P<0.0001)$. Rivaroxaban was associated with a nonsignificant reduction in intracranial hemorrhage in the elderly, whereas data on edoxaban in patients aged 75 years or older were not available. Finally, fatal bleeding was significantly reduced compared to VKA with dabigatran $110 \mathrm{mg}$, rivaroxaban, and both $30 \mathrm{mg}$ and $60 \mathrm{mg}$ doses of edoxaban in the total population; only rivaroxaban showed superiority in the elderly for this secondary outcome (OR 0.53 ; $95 \%$ CI $0.30-0.93 ; P=0.03)$; however, low numbers of fatal bleeding events in the elderly were reported in the studies. ${ }^{49}$

Caution should be exercised when any anticoagulant, DOAC or VKA, is given to an elderly patient. This age group represents the highest at risk for stroke and highest at risk for bleeding complications. ${ }^{1-3}$ Clinical trial evidence suggests greater efficacy with DOACs than VKA in the elderly population without an overt increased risk for major or CRNM bleeding; however, meta-analyses have shown distinct differences in bleeding outcomes among the elderly population. ${ }^{45,47-49}$ Dose adjustment may be considered on an individual basis to improve the risk profile. When used in NVAF, for example, apixaban should be limited in those aged $\geq 80$ years who also have an additional comorbidity such as renal impairment ( $\mathrm{SCr} \geq 1.5 \mathrm{mg} / \mathrm{dL}$ ) or frail or low body weight ( $\leq 60 \mathrm{~kg}$ ). While the FDA makes no recommendation for dose reduction of dabigatran in elderly patients, the European Union suggests using $110 \mathrm{mg}$ dabigatran twice daily for individuals aged 80 years and older. ${ }^{48}$ Finally, frailty should be considered when administering edoxaban for the indication of VTE treatment; a reduced dose of $30 \mathrm{mg}$ daily is recommended by the FDA in those weighing $(\leq 60 \mathrm{~kg})$ regardless of age. ${ }^{43}$

\section{Drug interactions}

Although DOACs have fewer drug interactions than conventional VKA, drug interactions with the P-glycoprotein
(P-gp) and CYP450 3A4 enzymes become important considerations with these agents. All DOAC metabolism is affected by P-gp such to the extent that they are not recommended to be given with P-gp inducers, rifampin being the most potent interaction cited due to its ability to decrease anticoagulant efficacy. ${ }^{39,42,43,50}$ However, inhibitors of P-gp can increase systemic exposure from DOACs and thereby increase bleeding risk. Dabigatran and edoxaban are mainly metabolized by P-gp, and dose reductions are recommended based on indication (NVAF or VTE) when renal function is impaired (an additional risk for bleeding). Rivaroxaban and apixaban are also metabolized through the liver and require dose adjustment to avoid bleeding risk when combined with strong CYP450 3A4 and P-gp inhibitors. Table 4 includes FDA-recommended dose adjustments to avoid increased risk for bleeding.

\section{Bleeding risk calculators}

An informed approach to bleeding assessment is necessary whenever oral anticoagulation is initiated. Several tools have been developed and validated to estimate rates of bleeding

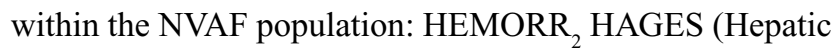
or Renal Disease, Ethanol Abuse, Malignancy, Older Age, Reduced Platelet Count or Function, Re-Bleeding, Hypertension, Anemia, Genetic Factors, Excessive Fall Risk and Stroke), HAS-BLED, and ATRIA (Anticoagulation Risk Factors in Atrial Fibrillation) scores; however, no tool is specific for the DOACs as these scoring systems have mainly been validated in patients receiving VKA. ${ }^{51-53}$ With these calculators, risk assessment points are allocated when a particular condition or risk factor is present; however, because risk factors for bleeding and stroke often overlap, patients at highest risk for stroke also have the highest bleeding risk scores. Score totals that indicate a high risk for bleeding with the HEMORR $_{2}$ HAGES, HAS-BLED, and ATRIA tools are $\geq 4$, $\geq 3$, and $\geq 5$, respectively. The HAS-BLED score has similar overall accuracy to HEMORR ${ }_{2}$ HAGES and has demonstrated similar accuracy in the ability to predict major bleeding. ${ }^{52}$ The HAS-BLED score has been shown to have the best predictive performance for major and CRNM bleeding compared to the HEMORR ${ }_{2}$ HAGES and ATRIA scoring tools. ${ }^{54}$ Furthermore, a HAS-BLED score of $>2$ correlated with a $85 \%$ increased risk in clinically relevant bleeding, 2.4-fold risk of major bleeding and 2.9-fold risk of death. ${ }^{54}$ An ATRIA score of $>3$ was not associated with clinically significant bleeding, but was associated with high all-cause mortality and major bleeding. ${ }^{54}$ While these tools may attempt to estimate risk for major and potentially fatal bleeding events, they offer 
poor differentiation between severity or type of bleed to anticipate. It is important to consider that a high bleeding risk score should not be considered a contraindication or reason to discontinue anticoagulation; in most cases, the benefit from anticoagulation outweighs the risk for bleeding. Rather, modified risks should be identified and corrected as appropriate to minimize bleeding risk. While American guidelines state lack of clinical utility, the use of a bleeding risk tool is recommended (class IIa, level of evidence B) by the European Society of Cardiology to determine modifiable bleeding risk in patients with atrial fibrillation. ${ }^{2,3}$ Despite comparisons between the risk calculators, no specific scale is recommended over another per European atrial fibrillation guidelines, but rather a combined risk identification utilizing several risk tools is offered. ${ }^{2}$

Risk estimations for bleeding from anticoagulation in those treated for VTE are limited (Table 5). Patient characteristics predictive of major bleeding have been identified through the RIETE (Registro Informatizado de Enfermedad TromboEmbólica) registry during the first 3 months of anticoagulation therapy for the treatment ofVTE. ${ }^{55}$ The American College of Chest Physicians recommends stratifying bleeding risk into low (0 risk factors), moderate ( 1 risk factor), and high ( $\geq 2$ risk factors). Each category is associated with $1.6 \%, 3.2 \%$, and $12.8 \%$ average major bleeding in the first
3 months of therapy with parental anticoagulation followed by warfarin for low-, moderate-, and high-risk categories, respectively. As in NVAF, a high bleeding risk score is not a reason to avoid anticoagulation. Rather, extended duration of anticoagulation for first unprovoked VTE may be avoided in those with highest bleeding risk. ${ }^{1}$

\section{Key exclusions from clinical trials}

Exclusion of patients with poor renal function, as previously discussed, is an important consideration for all of these clinical trials (Table 4). Patients with $\mathrm{CrCl}<25-30 \mathrm{~mL} / \mathrm{min}$ were excluded from VTE studies while $\mathrm{CrCl}<30 \mathrm{~mL} / \mathrm{min}$ was the cutoff for inclusion in NVAF trials. Patients with any history of intracranial bleeding were excluded from DOAC trials in NVAF $^{4-7}$ While all trials defined "high risk" for bleeding differently, history of previous stroke, TIA, or hemorrhage can increase the risk for subsequent events. In addition, time limits for some of these factors were incorporated into the exclusion criteria, such as stroke within 14 days or severe stroke within 6 months as implemented in the RE-LY trial to minimize bleeding risk. In addition, most trials excluded patients exhibiting hemodynamic instability, often defined by systolic and diastolic blood pressure thresholds, for example, systolic blood pressure $>180 \mathrm{mmHg}$ or diastolic blood pressure $>110 \mathrm{mmHg} .{ }^{5-10,12,13}$

Table 5 Bleeding risk assessment tools

\begin{tabular}{|c|c|c|c|c|}
\hline \multicolumn{3}{|l|}{ Atrial fibrillation } & \multicolumn{2}{|l|}{ VTE } \\
\hline $\begin{array}{l}\text { HEMORR }_{2} \text { HAGES } \\
\text { (assigned points) }\end{array}$ & $\begin{array}{l}\text { HAS-BLED }{ }^{52} \\
\text { (one point each) }\end{array}$ & $\begin{array}{l}\text { ATRIA }^{53} \\
\text { (assigned points) }\end{array}$ & $\begin{array}{l}\text { RIETE } 55 \\
\text { (assigned points) }\end{array}$ & $\begin{array}{l}\text { CHEST' }^{\prime} \\
\text { (one point each) }\end{array}$ \\
\hline $\begin{array}{l}\text { Liver/renal disease }(\mathrm{I}) \text {; age } \\
>75 \text { years }(\mathrm{I})\end{array}$ & $\begin{array}{l}\text { Abnormal liver or renal } \\
\text { function; elderly }\end{array}$ & $\begin{array}{l}\text { Severe renal disease/dialysis } \\
(3) \text {; age }>75 \text { years }(2)\end{array}$ & $\begin{array}{l}\mathrm{SCr}>1.2 \mathrm{~mL} / \mathrm{dL}(\mathrm{I} .5) ; \text { age } \\
>75 \text { years }(\mathrm{I})\end{array}$ & $\begin{array}{l}\text { Renal failure; age }>65 \text { years; } \\
\text { age }>75 \text { years }\end{array}$ \\
\hline $\begin{array}{l}\text { Anemia (I); low platelets } \\
(\mathrm{I}) \text {; history of bleeding }(2) \text {; } \\
\text { risk of re-bleeding (I) }\end{array}$ & $\begin{array}{l}\text { History or risk of } \\
\text { bleeding }\end{array}$ & $\begin{array}{l}\text { Anemia (3); prior } \\
\text { bleeding (I) }\end{array}$ & $\begin{array}{l}\text { Anemia }(1.5) \text {; recent } \\
\text { bleeding }(<15 \text { days })(2)\end{array}$ & Anemia; previous bleeding \\
\hline Alcohol abuse (I) & Drug/alcohol use & & & $\begin{array}{l}\text { Alcohol abuse } \\
\text { Antiplatelet therapy; NSAID } \\
\text { use }\end{array}$ \\
\hline & Labile INR & & & Poor anticoagulant control \\
\hline $\begin{array}{l}\text { Uncontrolled } \\
\text { hypertension (I) }\end{array}$ & $\begin{array}{l}\text { Uncontrolled } \\
\text { hypertension }\end{array}$ & Hypertension (I) & & \\
\hline Risk of falls or stroke (I) & History of stroke & & & $\begin{array}{l}\text { Previous stroke } \\
\text { Frequent falls }\end{array}$ \\
\hline Genetic factors (I) & & & Cancer (I); PE at baseline (I) & $\begin{array}{l}\text { Cancer; metastatic cancer } \\
\text { Diabetes } \\
\text { Comorbidity and reduced } \\
\text { functional capacity } \\
\text { Recent surgery }\end{array}$ \\
\hline $\begin{array}{l}\text { Low risk: } 0-\mathrm{I} \text {; } \\
\text { intermediate risk: } 2-3 \text {; } \\
\text { high risk: } \geq 4\end{array}$ & Low risk: $<3$; high risk: $\geq 3$ & $\begin{array}{l}\text { Low risk: } 0-3 \text {; intermediate } \\
\text { risk: } 4 \text {; high risk: } \geq 5\end{array}$ & $\begin{array}{l}\text { Low risk: } 0 \text {; intermediate } \\
\text { risk: } 1-4 \text {; high risk: }>4\end{array}$ & $\begin{array}{l}\text { Low risk: } 0 \text {; intermediate: I; } \\
\text { high risk } \geq 2\end{array}$ \\
\hline
\end{tabular}

Abbreviations: INR, international normalized ratio; NSAID, nonsteroidal anti-inflammatory drug; VTE, venous thromboembolism. 
Patients with active liver disease were excluded from all DOAC trials. Hepatic function should be assessed prior to therapy initiation and periodically thereafter. All DOACs are hepatically metabolized; however, dabigatran etexilate must undergo hydrolysis in the liver to be converted into its active compound. ${ }^{39}$ Use of rivaroxaban and edoxaban should be avoided in patients with moderate to severe hepatic disease; apixaban should be avoided in patients with severe hepatic disease. ${ }^{39,42,43,50}$

Finally, concomitant administration of antiplatelet and NSAID agents will increase the risk for bleeding via a synergistic response when given with DOACs and should be avoided or minimized when possible. ${ }^{17,18,20}$ ROCKET AF and Hokusai-VTE excluded patients receiving aspirin doses of $>100 \mathrm{mg}$ /day; both ARISTOTLE and AMPLIFY excluded those patients on $>165 \mathrm{mg}$ of aspirin daily or on dual antiplatelet therapy (DAPT). Use of aspirin was as high as $40 \%$ depending upon the study, and both aspirin and NSAID agents were noted to be independent risks for a bleeding event. ${ }^{17,18,20}$ Given the higher likelihood for GI bleeding with most DOACs, alternative analgesic medications should be considered when coadministration is necessary. Dabigatran is formulated with tartaric acid to increase oral bioavailability, which may have contributed to the increased risk of GI bleeding in RE-LY.,39

\section{Management of bleeding events}

Bleeding events from VKA use occurred in controlled trial settings in approximately 2.1 per 100 patient-years (range $0.90-3.4$ ) and 2.0 per 100 patient-years (range 0.2-7.6) in observational studies. ${ }^{56}$ As previously reviewed, GI bleeding may be more problematic with these agents, but overall bleeding is less likely to occur with DOACs. While bleeding events are rare, if they occur they are likely to be less severe and less likely to require extensive treatment intervention including transfusions. ${ }^{17-24}$ Laboratory measurement of blood or anticoagulant levels is not recommended during a bleeding event associated with DOACs as the reliability or value for any simple coagulation test in defining anticoagulation status has not been proven. Based on the DOAC half-lives and rapid clearance, supportive measures are typically sufficient while waiting for the anticoagulant effect to diminish, usually within 18-24 hours in patients with normal renal clearance. In life-threatening situations, or if surgical intervention is required emergently, the availability of a reversal agent is appealing. To date, three reversal agents have been studied and are in various stages of the approval process. The first specific antidote to be approved by the FDA and European Medicines Agency is idarucizumab and may be administered in a $5 \mathrm{~g}$ dose to reverse the effects of the direct thrombin inhibitor, dabigatran. ${ }^{57}$ Antidotes for the factor Xa inhibitors, among other anticoagulants, are in development and are summarized in Table 6.

\section{Cost-effectiveness}

In addition to proper patient selection and utilization of appropriate DOAC dosing, there are other factors to consider for enhanced patient care: quality of life, affordability, and patient preference. Quality and cost-effectiveness analysis have attempted to put perspective on DOAC use as compared to VKA.

While separate cost analyses have varied in the type of cohort studies included and in sources used to obtain drug

Table 6 Reversal agents for the DOACs ${ }^{57}$

\begin{tabular}{llll}
\hline Agent & Idarucizumab & Andexanet alfa & Ciraparantag \\
\hline Target & Dabigatran & Factor Xa inhibitors: & UFH \\
& & Rivaroxaban & Enoxaparin \\
& & Apixaban & Fondaparinux \\
& & Edoxaban & Dabigatran \\
& & Enoxaparin & Rivaroxaban \\
& & Fondaparinux & Apixaban \\
& & & Edoxaban \\
Mechanism & Humanized antibody fragment; & Recombinant modified human factor Xa & Small synthetic molecule; directly binds \\
& binds dabigatran with 350 times the & decoy protein; directly binds target and & drug target to block binding to target site \\
& affinity of thrombin & restores activity of factor Xa & \\
Onset & $<$ I0 minutes & $2-5$ minutes & 5-20 minutes \\
Approval status & FDA 20I5 & Currently delayed by FDA until more & FDA granted fast track review in April \\
& EMA 20I5 & data with edoxaban and enoxaparin & 20I5; currently in Phase III studies \\
Administration & Two consecutive IV infusions & Dose based on specific target & IV bolus; future studies may include infusion \\
& & anticoagulant; IV bolus with or without & \\
& infusion &
\end{tabular}

Abbreviations: DOACs, direct oral anticoagulants; EMA, European Medicines Agency; FDA, US Food and Drug Administration; IV, intravenous; UFH, unfractionated heparin. 
acquisition costs, several have been similar in recognizing apixaban as the most cost-effective agent for the prevention of stroke in NVAF. ${ }^{58-62}$ Using a Markov model to determine the quality-adjusted life years (QALY) and a willingnessto-pay (WTP) threshold of $\$ 50,000$, apixaban $5 \mathrm{mg}$ twice daily was the most cost-effective therapy (incremental costeffectiveness ratio [ICER] \$15,026/QALY), followed by dabigatran $150 \mathrm{mg}$ twice daily (ICER $\$ 11,150 / \mathrm{QALY}$ ) and rivaroxaban $20 \mathrm{mg}$ daily (ICER \$3,190/QALY) ${ }^{58}$ Another study utilizing a WTP threshold of $\$ 100,000$ had found that apixaban had an ICER of \$93,063/QALY, while rivaroxaban and dabigatran had an ICER/QALY of $\$ 111,465$ and $\$ 140,557$, respectively. ${ }^{62}$ It should be noted that TTR was not incorporated in either model. ${ }^{58,62}$

One cost-effective analysis in patients with NVAF accounted for patients with good and poor INR control, as defined by TTR $>75 \%$ and TTR $<60 \%$, respectively, and suggested that warfarin is a more cost-effective strategy if TTR is $>75 \%$. Using a WTP threshold of $\$ 50,000$ per QALY, the use of the DOACs was more cost-effective (ICER \$35,804) than warfarin with a low TTR $(<60 \%)$. However, the costeffectiveness of the three DOACs studied (dabigatran, rivaroxaban, apixaban) exceeded the $\$ 50,000$ WTP threshold when the $\mathrm{TTR}=70 \%$ and there was no additional cost or 1.5 -fold increase in cost to maintain the INR at that target. In addition, if warfarin was maintained at an INR between 2-3 at least $75 \%$ of the time, warfarin was a more cost-effective therapy even if the cost of the anticoagulation service was threefold higher. ${ }^{59}$

Later analyses including edoxaban continue to suggest better outcomes with the DOACs over VKA. In patients with an estimated $\mathrm{CrCl}>95 \mathrm{~mL} / \mathrm{min}$ at risk for bleeding events, apixaban has been identified as the superior cost-effective choice. ${ }^{61}$ However, when edoxaban was included (dosed appropriately for patients with $\mathrm{CrCl}<95 \mathrm{~mL} / \mathrm{min}$ ), the ICER was $\$ 77,565 /$ QALY and apixaban exceeded the $\$ 100,000$ WTP threshold. ${ }^{61}$ Multiple analyses have identified rivaroxaban as being the least cost-effective therapy. ${ }^{58,60,61}$

\section{Conclusion}

DOACs offer comparable and in some cases better efficacy and safety than traditional VKA therapy for multiple indications. While bleeding is generally reduced with DOAC use compared to warfarin, events can still occur. Location and severity of bleeding can vary based upon the anticoagulant chosen. Proper patient selection, including careful DOAC dose selection as guided by patient age, renal function, weight, and presence of drug interactions is prudent to minimize adverse events. Use of bleeding scoring systems can help to identify risks that should be modified while the patient is receiving anticoagulation. If bleeding occurs, severity and extent of treatment are generally less than that of those patients on VKA therapy and supportive measures can be utilized while therapeutic effect diminishes in most patients. Antidotes are reserved for life-threatening bleeding events or when emergent surgical intervention is required. Analyses indicate that DOACs, specifically apixaban and edoxaban (when appropriately dosed per renal function), are the most cost-effective options, particularly when TTR for INR control is low.

\section{Disclosure}

The authors report no conflicts of interest in this work.

\section{References}

1. Kearon C, Akl EA, Ornelas J, et al. Antithrombotic therapy for VTE disease: CHEST guideline and expert panel report. Chest. 2016;149(2):315-352.

2. Kirchhof P, Benussi S, Kotecha D, et al. 2016 ESC guidelines for the management of atrial fibrillation developed in collaboration with EACTS. Eur Heart J. 2016;37(38):2893-2962.

3. January CT, Wann LS, Alpert JS, et al. 2014 AHA/ACC/HRS guideline for the management of patients with atrial fibrillation: a report of the American College of Cardiology/American Heart Association Task Force on practice guidelines and the Heart Rhythm Society. Circulation. 2014;130(23):e199-e267.

4. Connolly SJ, Ezekowitz MD, Yusuf S, et al. Dabigatran versus warfarin in patients with atrial fibrillation. NEngl J Med. 2009;361(12):1139-1151.

5. Patel MR, Mahaffey KW, Garg J, et al. Rivaroxaban versus warfarin in nonvalvular atrial fibrillation. $N$ Engl J Med. 2011;365(10):883-891.

6. Granger CB, Alexander JH, McMurray JJV, et al. Apixaban versus warfarin in patients with atrial fibrillation. $N$ Engl $\mathrm{J} \mathrm{Med.}$ 2011;365(11):981-992.

7. Giugliano RP, Ruff CT, Braunwald E, et al. Edoxaban versus warfarin in patients with atrial fibrillation. NEngl J Med. 2013;369(22):2093-2104.

8. Schulman S, Kearon C, Kakkar AK, et al. Dabigatran versus warfarin in the treatment of acute venous thromboembolism. $N$ Engl J Med. 2009;361(24):2342-2352.

9. Bauersachs R, Berkowitz SD, Brenner B, et al; The EINSTEIN Investigators. Oral rivaroxaban for symptomatic venous thromboembolism. N Engl J Med. 2010;363(26):2499-2510.

10. Buller HR, Prins MH, Lensing AWA, et al; The EINSTEIN-PE Investigators. Oral rivaroxaban for the treatment of symptomatic pulmonary embolism. N Engl J Med. 2012;366(14):1287-1297.

11. Prins MH, Bauersachs R, Bellen B, et al; The EINSTEIN Investigators. Oral rivaroxaban versus standard therapy for the treatment of symptomatic venous thromboembolism: a pooled analysis of the EINSTEIN-DVT and PE randomized studies. Thromb J. 2013;11(1):21.

12. Agnelli G, Buller HR, Cohen A, et al; The AMPLIFY Investigators. Oral apixaban for the treatment of acute venous thromboembolism. $N$ Engl J Med. 2013;369(9):799-808.

13. Hokusai VTEI, Buller HR, Decousus H, et al. Edoxaban versus warfarin for the treatment of symptomatic venous thromboembolism. $N$ Engl J Med. 2013;369(15):1406-1415.

14. Huisman MV, Rothman KJ, Paquette M, et al. The changing landscape for stroke prevention in AF: findings from the GLORIA-AF registry phase 2. J Am Coll Cardiol. 2017;69(7):777-785.

15. Southworth MR, Reichman ME, Unger EF. Dabigatran and postmarketing reports of bleeding. N Engl J Med. 2013;368(14):1272-1274. 
16. McConeghy KW, Bress A, Qato DM, Wing C, Nutescu EA. Evaluation of dabigatran bleeding adverse reaction reports in the FDA adverse event reporting system during the first year of approval. Pharmacotherapy. 2014;34(6):561-569.

17. Majeed A, Hwang HG, Connolly SJ, et al. Management and outcomes of major bleeding during treatment with dabigatran or warfarin. Circulation. 2013;128(21):2325-2332.

18. Goodman SG, Wojdyla DM, Piccini JP, et al. Factors associated with major bleeding events: insights from the ROCKET AF trial (rivaroxaban once-daily oral direct factor Xa inhibition compared with vitamin $\mathrm{K}$ antagonism for prevention of stroke and embolism trial in atrial fibrillation). J Am Coll Cardiol. 2014;63(9):891-900.

19. Eerenberg ES, Middeldorp S, Levi M, Lensing AW, Buller HR. Clinical impact and course of major bleeding with rivaroxaban and vitamin $\mathrm{K}$ antagonists. J Thromb Haemost. 2015;13(9):1590-1596.

20. Hylek EM, Held C, Alexander JH, et al. Major bleeding in patients with atrial fibrillation receiving apixaban or warfarin: the ARISTOTLE trial (apixaban for reduction in stroke and other thromboembolic events in atrial fibrillation): predictors, characteristics, and clinical outcomes. J Am Coll Cardiol. 2014;63(20):2141-2147.

21. Bleker SM, Cohen AT, Buller HR, et al. Clinical presentation and course of bleeding events in patients with venous thromboembolism, treated with apixaban or enoxaparin and warfarin. Results from the AMPLIFY trial. Thromb Haemost. 2016;116(6):1159-1164.

22. Brekelmans MP, Bleker SM, Bauersachs R, et al. Clinical impact and course of major bleeding with edoxaban versus vitamin $\mathrm{K}$ antagonists. Thromb Haemost. 2016;116(1):155-161.

23. Ruff CT, Giugliano RP, Braunwald E, et al. Comparison of the efficacy and safety of new oral anticoagulants with warfarin in patients with atrial fibrillation: a meta-analysis of randomised trials. Lancet. 2014;383(9921):955-962.

24. Abraham NS, Singh S, Alexander GC, et al. Comparative risk of gastrointestinal bleeding with dabigatran, rivaroxaban, and warfarin: population based cohort study. BMJ. 2015;350:h1857.

25. Villines TC, Peacock WF. Safety of direct oral anticoagulants: insights from postmarketing studies. Am J Emerg Med. 2016;34(115):9-13.

26. Graham DJ, Reichman ME, Wernecke M, et al. Cardiovascular, bleeding, and mortality risks in elderly Medicare patients treated with dabigatran or warfarin for nonvalvular atrial fibrillation. Circulation. 2015;131(2):157-164.

27. Larsen TB, Rasmussen LH, Skjoth F, et al. Efficacy and safety of dabigatran etexilate and warfarin in "real-world" patients with atrial fibrillation: a prospective nationwide cohort study. $\mathrm{J} \mathrm{Am} \mathrm{Coll} \mathrm{Cardiol}$. 2013;61(22):2264-2273.

28. Hernandez I, Baik SH, Pinera A, Zhang Y. Risk of bleeding with dabigatran in atrial fibrillation. JAMA Intern Med. 2015;175(1):18-24.

29. Larsen TB, Skjoth F, Nielsen PB, Kjaeldgaard JN, Lip GY. Comparative effectiveness and safety of non-vitamin $\mathrm{K}$ antagonist oral anticoagulants and warfarin in patients with atrial fibrillation: propensity weighted nationwide cohort study. BMJ. 2016;353:i3189.

30. Halvorsen S, Ghanima W, Fride Tvete I, et al. A nationwide registry study to compare bleeding rates in patients with atrial fibrillation being prescribed oral anticoagulants. Eur Heart J Cardiovasc Pharmacother. 2017;3(1):28-36.

31. Noseworthy PA, Yao X, Abraham NS, Sangaralingham LR, McBane RD, Shah ND. Direct comparison of dabigatran, rivaroxaban, and apixaban for effectiveness and safety in nonvalvular atrial fibrillation. Chest. 2016;150(6):1302-1312.

32. Lip GY, Keshishian A, Kamble S, et al. Real-world comparison of major bleeding risk among non-valvular atrial fibrillation patients initiated on apixaban, dabigatran, rivaroxaban, or warfarin. A propensity score matched analysis. Thromb Haemost. 2016;116(5):975-986.

33. Deitelzweig S, Bruno A, Trocio J, et al. An early evaluation of bleedingrelated hospital readmissions among hospitalized patients with nonvalvular atrial fibrillation treated with direct oral anticoagulants. Curr Med Res Opin. 2016;32(3):573-582.
34. Bassand JP, Accetta G, Camm AJ, et al. Two-year outcomes of patients with newly diagnosed atrial fibrillation: results from GARFIELD-AF. Eur Heart J. 2016;37(38):2882-2889.

35. Lip GY, Huisman M, Diener HC, et al. Rates of strokes and bleeding with dabigatran 150 and $110 \mathrm{mg}$ in clinical practice: The GLORIA-AF Registry. Paper presented at: American College of Cardiology; 2017; Washington, DC.

36. Beyer-Westendorf J, Ebertz F, Forster K, et al. Effectiveness and safety of dabigatran therapy in daily-care patients with atrial fibrillation. Results from the Dresden NOAC Registry. Thromb Haemost. 2015;113(6):1247-1257.

37. Hecker J, Marten S, Keller L, et al. Effectiveness and safety of rivaroxaban therapy in daily-care patients with atrial fibrillation. Results from the Dresden NOAC Registry. Thromb Haemost. 2016;115(5): 939-949.

38. Camm AJ, Amarenco P, Haas S, et al. XANTUS: a real-world, prospective, observational study of patients treated with rivaroxaban for stroke prevention in atrial fibrillation. Eur Heart J. 2016;37(14):1145-1153.

39. Pradaxa [package insert]. Ridgefield, CT: Boehringer Ingelheim Pharmaceuticals, Inc; 2011

40. Hariharan S, Madabushi R. Clinical pharmacology basis of deriving dosing recommendations for dabigatran in patients with severe renal impairment. J Clin Pharmacol. 2012;52(1 suppl):119S-125S.

41. Lehr T, Haertter S, Liesenfeld KH, et al. Dabigatran etexilate in atrial fibrillation patients with severe renal impairment: dose identification using pharmacokinetic modeling and simulation. J Clin Pharmacol. 2012;52(9):1373-1378.

42. Xarelto [package insert]. Titusville, NJ: Janssen Pharmaceuticals, Inc; 2011.

43. Savaysa [package insert]. Parsippany, NJ: Daiichi Sankyo, Inc; 2015.

44. Deedwania PC. New oral anticoagulants in elderly patients with atrial fibrillation. Am J Med. 2013;126(4):289-296.

45. Barco S, Cheung YW, Eikelboom JW, Coppens M. New oral anticoagulants in elderly patients. Best Pract Res Clin Haematol. 2013;26(2): 215-224.

46. Hylek EM, Evans-Molina C, Shea C, Henault LE, Regan S. Major hemorrhage and tolerability of warfarin in the first year of therapy among elderly patients with atrial fibrillation. Circulation. 2007;115(21):2689-2696.

47. Halperin JL, Hankey GJ, Wojdyla DM, et al. Efficacy and safety of rivaroxaban compared with warfarin among elderly patients with nonvalvular atrial fibrillation in the rivaroxaban once daily, oral, direct factor Xa inhibition compared with vitamin $\mathrm{K}$ antagonism for prevention of stroke and embolism trial in atrial fibrillation (ROCKET AF). Circulation. 2014;130(2):138-146.

48. Sardar P, Chatterjee S, Chaudhari S, Lip GY. New oral anticoagulants in elderly adults: evidence from a meta-analysis of randomized trials. $J$ Am Geriatr Soc. 2014;62(5):857-864.

49. Sharma M, Cornelius VR, Patel JP, Davies JG, Molokhia M. Efficacy and harms of direct oral anticoagulants in the elderly for stroke prevention in atrial fibrillation and secondary prevention of venous thromboembolism: systematic review and meta-analysis. Circulation. 2015;132(3):194-204.

50. Eliquis [package insert]. Princeton, NJ: Bristol-Myers Squibb Company; 2012.

51. Gage BF, Yan Y, Milligan PE, et al. Clinical classification schemes for predicting hemorrhage: results from the National Registry of Atrial Fibrillation (NRAF). Am Heart J. 2006;151(3):713-719.

52. Pisters R, Lane DA, Nieuwlaat R, de Vos CB, Crijns HJ, Lip GY. A novel user-friendly score (HAS-BLED) to assess 1-year risk of major bleeding in patients with atrial fibrillation: the Euro Heart Survey. Chest. 2010;138(5):1093-1100.

53. Fang MC, Go AS, Chang Y, et al. A new risk scheme to predict warfarin-associated hemorrhage: the ATRIA (Anticoagulation and Risk Factors in Atrial Fibrillation) Study. J Am Coll Cardiol. 2011;58(4): 395-401. 
54. Apostolakis S, Lane DA, Guo Y, Buller H, Lip GY. Performance of the HEMORR(2)HAGES, ATRIA, and HAS-BLED bleeding riskprediction scores in patients with atrial fibrillation undergoing anticoagulation: the AMADEUS (evaluating the use of SR34006 compared to warfarin or acenocoumarol in patients with atrial fibrillation) study. J Am Coll Cardiol. 2012;60(9):861-867.

55. Ruiz-Gimenez N, Suarez C, Gonzalez R, et al. Predictive variables for major bleeding events in patients presenting with documented acute venous thromboembolism. Findings from the RIETE Registry. Thromb Haemost. 2008;100(1):26-31.

56. Roskell NS, Samuel M, Noack H, Monz BU. Major bleeding in patients with atrial fibrillation receiving vitamin $\mathrm{K}$ antagonists: a systematic review of randomized and observational studies. Europace. 2013;15(6):787-797.

57. Rogers KC, Shelton MP, Finks SW. Reversal agents for direct oral anticoagulants. Cardiol Rev. 2016;24:310-315.
58. Harrington AR, Armstrong EP, Nolan PE Jr, Malone DC. Costeffectiveness of apixaban, dabigatran, rivaroxaban, and warfarin for stroke prevention in atrial fibrillation. Stroke. 2013;44(6):1676-1681.

59. You JH. Novel oral anticoagulants versus warfarin therapy at various levels of anticoagulation control in atrial fibrillation - a cost-effectiveness analysis. J Gen Intern Med. 2014;29(3):438-446.

60. Shah A, Shewale A, Hayes CJ, Martin BC. Cost-effectiveness of oral anticoagulants for ischemic stroke prophylaxis among nonvalvular atrial fibrillation patients. Stroke. 2016;47(6):1555-1561.

61. Hernandez I, Smith KJ, Zhang Y. Cost-effectiveness of non-vitamin $\mathrm{K}$ antagonist oral anticoagulants for stroke prevention in patients with atrial fibrillation at high risk of bleeding and normal kidney function. Thromb Res. 2017;150:123-130.

62. Canestaro WJ, Patrick AR, Avorn J, et al. Cost effectiveness or oral anticoagulants for treatment of atrial fibrillation. Circ Cardiovasc Qual Outcomes. 2013;6:724-731.

\section{Publish your work in this journal}

Vascular Health and Risk Management is an international, peerreviewed journal of therapeutics and risk management, focusing on concise rapid reporting of clinical studies on the processes involved in the maintenance of vascular health; the monitoring, prevention and treatment of vascular disease and its sequelae; and the involvement of metabolic disorders, particularly diabetes. This journal is indexed on PubMed Central and MedLine. The manuscript management system is completely online and includes a very quick and fair peer-review system, which is all easy to use. Visit http://www.dovepress.com/ testimonials.php to read real quotes from published authors. 